\title{
Progress and limitations in cancer gene therapy
}

Dae Seog Heo, MD, PhD

This is a brief discussion on the progress of gene therapy and the limitations of present-day gene therapy clinical trials based on a review of 464 human trial protocols from the U.S. National Institutes of Health (NIH) and the U.S. Federal Drug Administration (FDA). The paper also discusses an aspect of the gene therapy research of the author, who, together with colleagues, conducted the first gene therapy clinical trial in Korea in 1995. Genet Med 2002:

4(6, Supplement):52S-55S.

Gene therapy can be defined as a therapeutic technique in which functioning genes are inserted into the cells of a patient to correct an inborn genetic error (gene replacement therapy) or to provide a new function to the cell (gene addition therapy). Since the first clinical trial in 1990, there have been more than 400 clinical protocols. However, in 1999, there was one casualty in a gene therapy trial at the University of Pennsylvania. Since that incident, there has been a sharp decline in gene therapy clinical trials. ${ }^{1-4}$

To evaluate the problems regarding gene therapy clinical trials, 464 human trial protocols from the NIH and FDA that had been performed up to May 15, 2001, were reviewed. Of those, 62\% (290/464 protocols) were for the control of cancer. Other categories are HIV infection, monogenic diseases such as hemophilia, and marking studies (Fig. 1). Cancer has been the most important disease for clinical trials of gene therapy worldwide because getting approval for a human trial is easier for cancer than for other genetic diseases. In Korea, there have been three clinical trials, and they involved only patients with cancer.

\section{Current status of cancer gene therapy}

Over the last 10 years, cancer has become the most important disease entity in gene therapy. Ten categories of cancer gene therapy are suggested from the NIH database. Of those, $60 \%$ of the clinical trials are the genetic modulation of the immune response (in vitro or in vivo). Other kinds of approaches are listed in Table 1.

There are two primary strategies for cancer gene therapy (Fig. 2). One is an immunologic target; the other is a molecular target. Molecular targets include oncogenes, tumor suppressor genes, and genes that regulate drug sensitivity. Two-thirds of

From the Department of Internal Medicine, Seoul National University Hospital, Cancer Research Institute, Seoul National University Medical College, Seoul, Korea.

Dae Seog Heo, MD, PhD, Associate Professor, Department of Internal Medicine, Seoul National University Hospital, Cancer Research Institute, Seoul National University Medical College, 110-744, 22 Yongon-dong, Chongno-gu, Seoul 110-799, Korea.

Received: June 27, 2002

Accepted: September 24, 2002.

DOI: 10.1097/01.GIM.0000041437.24987.CE cancer gene therapy are related to immunologic targets, such as cytokine genes, and one-third is focused on molecular targets (Table 2).

\section{Molecular targets}

It has been well hypothesized that tumor initiation and progression are based on oncogene activation or the inactivation of tumor suppressor genes. Gene therapy can down-regulate oncogenes by antisense. Antisense, the use of oligonucleotides made to be complementary to a particular mRNA in the $3^{\prime}-5^{\prime}$ rather than $5^{\prime}-3^{\prime}$ orientation, can lead to growth inhibition of cancer cell lines in animal studies. However, in human trials, antisense strategy showed only limited efficacy.

The other strategy is to reinstitute tumor suppressor genes by gene transfer. Among the tumor suppressor genes, the $p 53$ story is most exciting. ${ }^{5-7}$ Clinical trials using the $p 53$ gene have been done in several tumors. In non-small-cell lung cancer, p53 was introduced using an adenoviral vector with cisplatin chemotherapy. Of 24 patients in an American study, only 2 showed an objective clinical response. ${ }^{6}$ In a European study, ${ }^{7}$ a combination of $p 53$ gene therapy with cisplatin chemotherapy was compared with cisplatin chemotherapy alone. There was no difference between the two groups. At the moment, $p 53$ gene therapy is not effective for non-small-cell lung cancer.

Other gene therapy trials using molecular targets are in progress. The herpes simplex thymidine kinase (HSVtk) and cytosine deaminase $(C D)$ genes are being transfected to tumor cells as drug sensitivity genes to activate prodrugs into anticancer drugs. ${ }^{1,8}$ The transfer of the HSVtk gene to a tumor followed by antiviral agent therapy (a suicidal vector trial) enjoyed great success in animal trials. Culver and Blaese ${ }^{8}$ introduced HSVtk genes into an experimental brain tumor model and treated the animals with ganciclovir. The brain tumor was eliminated without affecting normal brain tissue. However, other clinical trials did not confirm the NIH results.

Yet other trials include insertion of $M D R$ genes into normal bone marrow to confer a drug-resistant phenotype. Gottesman's group ${ }^{9}$ intended to treat cancer patients with high-dose chemotherapy and transplantation of autologous MDR-containing bone marrow without serious hematologic side effects. 


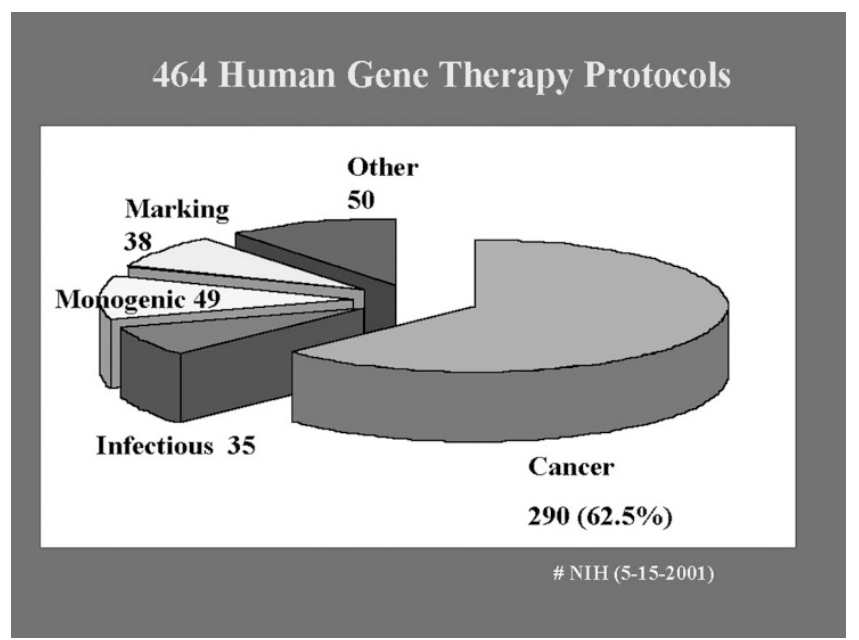

Fig. 1 Categories of clinical trials of gene therapy (based on http://www4.od.nih.gov/ oba/rac/hgtprep.asp).

Table 1

Categories of cancer gene therapy

\begin{tabular}{lc}
\hline Category & Quantities: $n(\%)$ \\
\hline Antisense & 6 \\
Chemoprotection & $12(4)$ \\
Immunotherapy/in vitro & $81(28)$ \\
Immunotherapy/in vivo & $100(34)$ \\
Pro-drug/HSVtk & $37(13)$ \\
Tumor suppressor gene & $34(12)$ \\
Single chain antibody & 2 \\
Oncogene down-regulation & 7 \\
Vector-directed cell lysis & $10(3)$ \\
Dominant negative mutation & 1 \\
\hline
\end{tabular}

Information derived from http://www4.od.nih.gov/oba/rac/hgtprep.asp.

The problems were low transfection efficiency and risk of transfection of the MDR gene into contaminating tumor cells.

The major limitations of in vivo nonimmunologic approaches are targeting selectivity and transfection efficiency. Not only is it very difficult to attack tumor cells without affecting normal cells, but less than 5\% of tumor cells can be transfected after the addition of foreign genes.

\section{Immunologic targets}

Because of theoretical limitations and poor clinical results with cancer gene therapy with molecular targets, most clinical trials concentrate on immunologic targets. Among many strategies, genetic modulation of the immune response is the hottest area of clinical cancer research.

The first clinical trial using gene therapy strategy was with tumor-infiltrating lymphocytes (TILs) transduced with the gene for TNF- $\alpha$. The approach was designed to use TILs for the

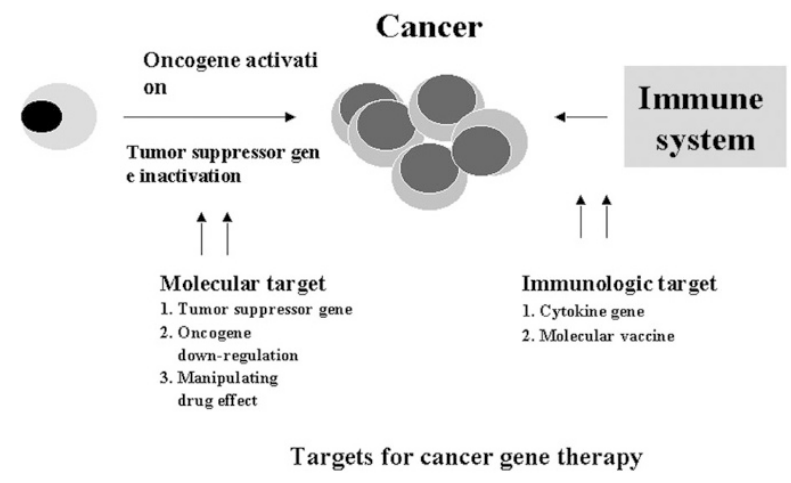

Fig. 2 Cancer gene therapy strategies.

Table 2

Classification of cancer gene therapy based on targets

A. Molecular targets

1. Tumor suppressor gene therapy

2. Down-regulation of oncogenes

3. Manipulating drug effects (sensitivity/resistance)

B. Immunologic targets

1. Passive immune modulation-immune effector cells transfected with cytokine genes

2. Active immune modulation

a. Genetically modified cells-tumor cells transfected with cytokine genes

b. Molecular vaccine-tumor antigens (MART-1, gp100, CEA, PSA)

purpose of effective production of TNF- $\alpha$ at the tumor site without systemic side effects. Effective systemic TNF- $\alpha$ blood levels (400-500 $\mu \mathrm{g} / \mathrm{kg} /$ day in mice) were unattainable because of systemic side effects (maximum tolerated dose in human trial: $8 \mu \mathrm{g} / \mathrm{kg} /$ day). However, problems with the TILs' inadequate expression of the transduced TNF- $\alpha$ gene (expression blockade) and ineffective delivery of TILs to the tumor site (traffic) limited the effectiveness.

In contrast, in vitro modulation of tumor cells using cytokine genes gave us the new possibility of a tumor vaccine (tumor-cell directed lymphokine gene therapy). Among the strategies to activate host immune response to cancer, cytokine gene therapy has been evaluated most extensively. ${ }^{10,11}$

Various cytokine genes (interleukins, interferons, GM-CSF, etc.) have been introduced into tumor cells to increase immunogenicity (increase immune recognition by immune effector cells). Data from animal experiments indicate that this approach can offer systemic antitumor immunity based on the observation of decreased tumorigenesis of genetically modified tumor cells and the rejection of subsequent injection of unmodified tumor cells. However, it is not clear whether this approach can eradicate established tumors in tumor-bearing animals.

We have explored the possibility of genetic modulation of the immune response against cancer. Among cytokine genes, 
the introduction of both GM-CSF and IFN- $\gamma$ genes into tumor cells showed synergistic effects in vitro and in animal experiments. ${ }^{12}$ Although there have been numerous clinical trials using cytokine genes, there is still no convincing evidence to support the clinical efficacy of cytokine gene therapy. ${ }^{13,14}$

The first clinical trial of human gene therapy in Korea was conducted using the HLA-B7/ $\beta 2$-microglobulin gene. Intratumoral injection of the therapeutic gene induced two clinical responses out of nine patients. All patients showed an increase in natural killer (NK) activity in their circulating peripheral blood lymphocytes. ${ }^{15}$

The purpose of the study was to assess the therapeutic potential of injecting the gene for HLA-B7/ $\beta 2$-microglobulin into the subcutaneous metastatic nodules of patients who are refractory to conventional treatments (Fig. 3). The nine patients evaluated were divided into three groups and given escalating doses of DNA (20,40, and $100 \mu \mathrm{g}$ of the HLA-B7 plasmid DNA/lipid complex for each group) every 2 weeks. Biopsy specimens from the treated tumor nodules of all nine
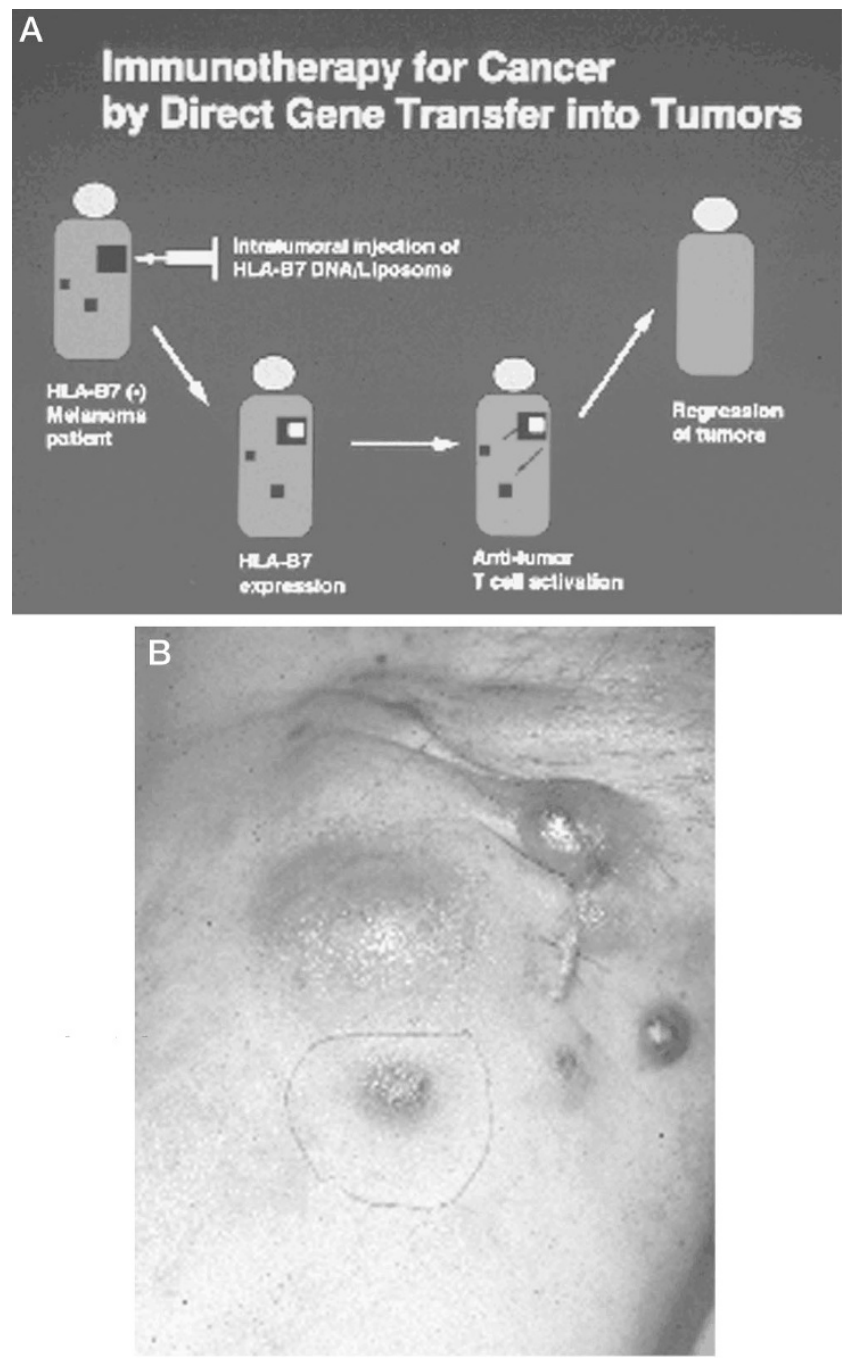

Fig. 3 A: strategy of intratumoral injection of HLA-B7/ $\beta 2$-microglobulin gene in patients with cancer. B: subcutaneous metastatic nodules in a melanoma patient. patients were positive for the presence of DNA and for HLA-B7 mRNA expression. Moreover, in six of the nine patients, immunohistology of tumor biopsy samples revealed the expression of recombinant HLA-B7 protein. Also, all nine patients showed an increase in NK activity in their circulating peripheral blood lymphocytes. In two lung cancer patients, one partial response and one mixed response were observed after gene transfer. These responses were confined to the treated nodules and the untreated locoregional lymph nodes; the lung masses showed no regression. Remission durations were 14 and 6 weeks, respectively, and in a total of 35 cycles, no significant toxicities were observed. Immunohistologic analysis revealed an increased infiltration of CD4 $+\mathrm{T}$ cells, macrophages, and NK cells after therapy. In the two responding cases, direct intratumoral injection of an allogeneic class I gene could elicit an antitumor response in locoregional areas, possibly through the activation of NK cells. ${ }^{15}$

Genes for tumor-specific antigeneic determinants like CEA (carcino-embryonic antigen), PSA (prostate-specific antigen), MART-1, or gp100, are being explored for therapy. ${ }^{16}$

\section{Limitations and prospects}

Despite some promising results in cancer gene therapy, there are many limitations to overcome. ${ }^{17-19}$ Only a limited number of therapeutic genes can be used in clinical trials.

Vectors are not efficient in vivo. Although the high transfection efficiency with adenovirus in vitro is well documented, it is still not clear whether adenoviral vectors are effective in vivo in solid tumor models. In our experiment, transduction of tumor tissue was limited to just around the injection site after intratumoral injection of the adenoviral vector. ${ }^{19}$ In our experiment, tumor cells showed depressed expression of the CAR (coxsackie-adenovirus receptor) gene for adenoviral vector in comparison to normal cells.

The basic elements of gene therapy consist of therapeutic genes, vectors, and strategies (Fig. 4). As more information about cloned genes becomes available through various pro-

\section{Cancer Gene Therapy}

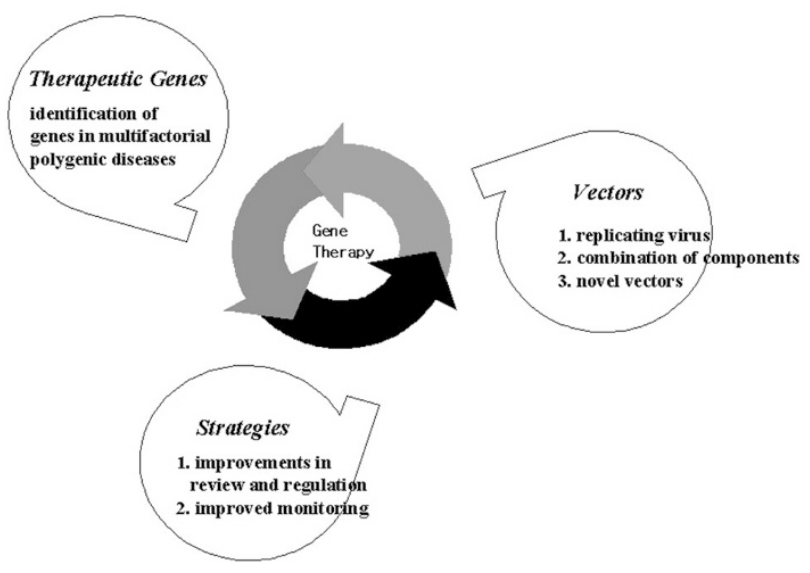

Fig. 4 Three essential elements for gene therapy. 
grams, such as the Human Genome Project, the potential of gene therapy expands. Genes of interest can be inserted into various target cells, such as immune effector cells, tumor cells, and hematopoietic stem cells.

Recent trials with an oncolytic virus showed promise. ${ }^{20} \mathrm{~A}$ phase II trial in recurrent head and neck cancer demonstrated three complete and two partial remissions out of 40 patients with replication-competent adenoviral vector (ONYX-015). ${ }^{21}$ A phase III clinical trial is presently going on.

There have been remarkable developments in our understanding of the molecular basis of human cancer, and the enormous potential of the use of gene therapy to not only cure cancer, but to also prevent it, is anticipated. However, clinical trials have so far showed no definite advantages of gene therapy over conventional modalities. To make gene therapy a standard treatment modality for cancer patients, more improvements are needed in areas such as therapeutic genes and vectors. Many ethical and technical hurdles still remain.

\section{Acknowledgment}

This work was supported by the Korea Science and Engineering Foundation (KOSEF) through the Molecular Therapy Research Center.

\section{References}

1. Hwu P. Gene therapy. In: DeVita VT, Hellman S, Rosenberg SA, editors. Cancer principles and practice of oncology, 6th ed. Philadelphia: Lippincott Williams \& Wilkins, 2001:3161-3180.

2. Mastrangelo MJ, Berd D, Nathan FE, Lattime EC. Gene therapy for human cancer: an essay for clinicians. Semin Oncol 1996;23:4-21.

3. Marshall E. Gene therapy's growing pains. Science 1995;269:1050-1055.

4. Tournier-Lasserve E. Gene therapy and beyond. Lancet 1999;354(suppl):22.

5. Clayman GL, el-Naggar AK, Lippman SM, Henderson YC, Frederick M, Merritt JA, Zumstein LA, Timmons TM, Liu TJ, Ginsberg L, Roth JA, Hong WK, Bruso P, Goepfert H. Adenovirus-mediated $p 53$ gene transfer in patients with advanced recurrent head and neck squamous cell carcinoma. J Clin Oncol 1998;16:2221-2232.

6. Nemunaitis J, Swisher SG, Timmons T, Connors D, Mack M, Doerksen L et al. Adenovirus-mediated $p 53$ gene transfer in sequence with cisplatin to tumors of patients with non-small-cell lung cancer. J Clin Oncol 2000;18:609-622.
7. Schuler M, Herrmann R, De Greve JL, Stewart AK, Gatzemeier U, Stewart DJ, Laufman L, Gralla R, Kuball J, Buhl R, Heussel CP, Kommoss F, Perruchoud AP, Shepherd FA, Fritz MA, Horowitz JA, Huber C, Rochlitz C. Adenovirus-mediated wild-type $p 53$ gene transfer in patients receiving chemotherapy for advanced nonsmall-cell lung cancer: results of a multicenter phase II study. J Clin Oncol 2001;19: $1750-1758$.

8. Culver KW, Blaese RM. Gene therapy of cancer. Trends Genetics 1994;10:174-178.

9. Sorrentino BP, Brandt SJ, Bodine D, Gottesman M, Pastan I, Cline A, Nienhuis AW Selection of drug-resistant bone marrow cells in vivo after retroviral transfer of human MDR1. Science 1992;257:99-103,

10. Dranoff G, Jaffe E, Lazenby A, Golumbek P, Levitsky H, Brose K, Jackson V, Hamada $\mathrm{H}$, Pardoll D, Mulligan RC. Vaccination with irradiated tumor cells engineered to secrete murine granulocyte-macrophage colony-stimulating factor stimulates potent, specific, and long-lasting anti-tumor immunity. Proc Nat Acad Sci 1993;90: 3539-3543.

11. Tepper RI, Mule JJ. Experimental and clinical studies of cytokine gene-modified tumor cells. Human Gene Ther 1994;5:153-164.

12. Yoon SJ, Heo DS, Kang JO, Lee SG, Kim CD, Sung MW, Kim NK. Synergistic anti-tumor effects with co-expression of GM-CSF and IFN-gamma in murine tumors. Int J Cancer 1998;77:907-912.

13. Dranoff G. Cancer gene therapy. Connecting basic research with clinical inquiry. J Clin Oncol 1998;16:2548-2556.

14. Parmiani G, Rodolfo M, Melani C. Immunological gene therapy with ex vivo genemodified tumor cells: a critique and a reappraisal. Hum Gene Ther 2000;11:12691275 .

15. Heo DS, Yoon SJ, Kim WS, Lee KH, Seol JG, Lee SG, Jung CW, Cho E, Kim CW, Park MH, Sung MW, Kim KH, Bang YJ, Kim NK. Locoregional response and increased natural killer activity after intratumoral injection of HLA-B7/beta2-microglobulin gene in patients with cancer. Hum Gene Ther 1998;9:2031-2038.

16. Harris JD, Lemoine NR. Strategies for targeted gene therapy. Trends Genet 1996;12: $400-405$.

17. Roth JA, Cristiano RJ. Gene therapy for cancer: what have we done and where are we going? J Natl Cancer Inst 1997;89:21-39.

18. Vile RG, Russell SJ, Lemoine NR. Cancer gene therapy: hard lessons and new courses. Gene Ther 2000;7:2-8.

19. Lee SG, Yoon SJ, Kim CD, Kim K, Lim DS, Yeom YI, Sung MW, Heo DS, Kim NK. Enhancement of adenoviral transduction with polycationic liposomes in vivo. Cancer Gene Ther 2000;7:1329-1335.

20. Pawlik TM, Nakamura H, Yoon SS, Mullen JT, Chandraesekhar S, Chiocca EA, Tanabe KK. Oncolysis of diffuse hepatocellular carcinoma by intravascular administration of a replication-competent, genetically engineered herpesvirus. Cancer Res 2000;60:2790-2795.

21. Nemunaitis J, Khuri F, Ganly I, Arseneau J, Posner M, Vokes E, Kuhn J, McCarty T, Landers S, Blackburn A, Romel L, Randlev B, Kaye S, Kirn D. Phase II trial of intratumoral administration of ONYX-015, a replication-selective adenovirus, in patients with refractory head and neck cancer. J Clin Oncol 2001;19:289-298. 